Article

\title{
Preparation and Evaluation of Novel Transfersomes Combined with the Natural Antioxidant Resveratrol
}

\author{
Pey-Shiuan Wu ${ }^{1}$, Yu-Syuan Li ${ }^{1}$, Yi-Ching Kuo ${ }^{1}$, Suh-Jen Jane Tsai ${ }^{2}$ and Chih-Chien Lin ${ }^{1, *(D)}$ \\ 1 Department of Cosmetic Science, Providence University, Taichung 43301, Taiwan; jwu2@pu.edu.tw (P.-S.W.); \\ g1060037@gm.pu.edu.tw (Y.-S.L.); sin14990@gmail.com (Y.-C.K.) \\ 2 Department of Applied Chemistry, Providence University, Taichung 43301, Taiwan; sjtsai@pu.edu.tw \\ * Correspondence: chchlin@pu.edu.tw; Tel.: +886-4-2632-8001 (ext. 15409)
}

Academic Editors: Susana M. Cardoso and Alessia Fazio

Received: 23 December 2018; Accepted: 6 February 2019; Published: 8 February 2019

check for updates

\begin{abstract}
Resveratrol (tran-3,5, $4^{\prime}$-trihydroxystibene, RSV) is a kind of polyphenol which has anti-inflammatory, antioxidant, anti-allergy, and anti-cancer properties, as well as being a scavenger of free radicals and preventing cardiovascular diseases. However, it is quite unstable in light, heat, and other conditions, and decays easily due to environmental factors. For these reasons, this study used a new type of carrier, transfersome, to encapsulate RSV. Transfersome consists of phosphatidyl choline (PC) from a liposomal system and non-ionic edge activators (EA). EA are an important ingredient in the formulation of transfersome; they can enhance the flexibility of the lipid bimolecular membrane of transfersome. Due to its ultradeformability, it also allows drugs to penetrate the skin, even through the stratum corneum. We hope that this new encapsulation technique will improve the stability and enhance the permeability of RSV. Concluding all the tested parameters, the best production condition was 5\% PC/EA (3:1) and 5\% ethanol in distilled water, with an ultrasonic bath and stirring at $500 \mathrm{rpm}$, followed by high pressure homogenization. The optimal particle size was $40.13 \pm 0.51 \mathrm{~nm}$ and the entrapment efficiency (EE) was $59.93 \pm 0.99 \%$. The results of antioxidant activity analysis showed that transfersomes were comparable to the RSV group (unencapsulated). During in vitro transdermal delivery analysis, after $6 \mathrm{~h}, \mathrm{D} 1-20(\mathrm{~W})$ increased $27.59 \%$ by accumulation. Cell viability assay showed that the cytotoxicity of D3-80(W) was reduced by $34.45 \%$ compared with the same concentration of RSV. Therefore, we successfully prepared RSV transfersomes and also improved the stability, solubility, and safety of RSV.
\end{abstract}

Keywords: resveratrol; transfersome; natural antioxidant; edge activators; liposomal technique

\section{Introduction}

Resveratrol (tran-3,5,4'-trihydroxystibene, RSV), also known as polydatin, piceid, and grape polyphenol, is a kind of polyphenol that is present in plants. It is usually found in grape skin, mulberry, peanuts, and red wine. RSV has been shown to modulate the metabolism of lipids; it also has anti-inflammatory, antioxidant, anti-allergy, and anti-cancer properties, as well as being a scavenger of free radicals, anti-allergy, and preventing cardiovascular diseases, for example, and used in the prevention and treatment of atherosclerosis and hyperlipidemia [1,2]. Several studies have pointed out that RSV is an effective preventive medicine for cancers: It can inhibit the growth of tumors and thus help prevent cancers [3-5]. RSV belongs to the polyphenols. In terms of its antioxidant capacity, RSV has an aromatic ring structure as well as an $\mathrm{OH}$ group that provides electrons. The use of peroxides on unpaired electrons, including lipids, proteins, or free radical products generated in the electron transport chain that undergo oxygen-consuming reactions, can terminate resveratrol's free radical chain reaction to reach its antioxidant capacity [6]. In addition to antioxidant activity, RSV has been found to have anti-inflammatory properties as well. According to previous animal- and 
cell-based studies, RSV exhibited the ability to inhibit the COX enzyme activity and further confirmed its anti-inflammatory mechanism $[7,8]$.

Since RSV has poor water solubility [9], instability [10], and low bioavailability, its applications in cosmetics, foods, and drugs have been extremely limited. Therefore, the use of proper carriers may potentially improve the above problems. For example, liposome has been used in cosmetics for many years [11,12]. It has good compatibility with the skin, with no reported allergies, will degrade into phospholipids, and become part of the cell membrane. However, due to its tight structure, liposome lacks flexibility, which also affects the transdermal penetration of active compounds.

In 1992, Cevc and Blume developed a novel transfersome consisting of a phosphatidyl choline (PC) and a non-ionic edge activator (EA), called "Transfersome" [13,14]. Phosphatidyl choline is the main component of the biomembrane, consisting of a hydrophilic polar head group of a phosphate group and two hydrophobic fatty acid chains. EA is a structure having both hydrophilicity and hydrophobicity, and a single chain surfactant with a large curvature is generally used, which destabilizes the lipid bilayer of the vesicles and increases the ultradeformability of the bilayer by lowering its interfacial tension. It also relatively affects the physical properties of the transfersome $[15,16]$. Therefore, it easily penetrates through skin pores much smaller than itself to achieve transdermal penetration and prolong the release and increase the activity of the drug [17-19]. However, until now, there have been no any studies focused on the development of RSV transfersome.

Therefore, in this study, we used transfersome as a novel carrier to encapsulate resveratrol, through the testing of different ratios of PC/EA and ethanol content on the entrapment efficiency (EE), particle size distribution, and zeta potential of transfersome. It is expected that the encapsulation technique with the best preparation conditions will improve the stability of resveratrol, increase the penetration, and also reduce the cytotoxicity.

\section{Results}

\subsection{Characteristics of Transfersomes}

In the study, we successfully prepared transfersomes using a high-pressure homogenization technique. Different edge activators, Tween 20, Plantacare ${ }^{\circledR} 1200$ UP, and Tween 80, were used to find out the proper formulation for RSV transfersome. In addition, several important parameters of the production process were also evaluated in the experiments.

The results of the particle sizes, polydispersity index (PDI), and entrapment efficiency of transfersomes are shown in Table 1. The results of different proportions of PC/EA could show that the particle sizes of the A, B, and C groups were all less than $100 \mathrm{~nm}$. Among them, the better entrapment efficiencies in the B group were $62.21 \%$ to $67 \%$. At low EA concentrations (C group), EA was incorporated within the lipid bilayer according to the partition equilibrium between the aqueous and lipid phase, resulting in limited drug partition equilibrium caused by the production of fewer vesicles. Increasing EA-induced vesicle growth and imparting fluidity to the membrane bilayer resulted in improved EE (B group). Additionally, the pore generation due to a high concentration of EA led to leakage of the vesicles, resulting in high drug loss and, hence, low drug entrapment (C group). 
Table 1. Entrapment efficiency (EE) and particle sizes of transfersomes.

\begin{tabular}{ccccccc}
\hline - & \multicolumn{2}{c}{ Particle Size (nm) } & \multicolumn{2}{c}{ PDI } & \multicolumn{2}{c}{ EE (\%) } \\
\hline - & 0 Days & 14 Days & 0 Days & 14 Days & 0 Days & 14 Days \\
\hline A1-20(B) & $48.34 \pm 0.19$ & $49.27 \pm 0.47$ & $0.145 \pm 0.007$ & $0.166 \pm 0.005$ & $39.76 \pm 2.70$ & $25.19 \pm 1.26$ \\
A2-12(B) & $56.35 \pm 0.31$ & $58.53 \pm 0.66$ & $0.128 \pm 0.016$ & $0.119 \pm 0.018$ & $33.31 \pm 0.87$ & $24.85 \pm 2.27$ \\
A3-80(B) & $64.53 \pm 0.41$ & $66.32 \pm 0.30$ & $0.042 \pm 0.011$ & $0.041 \pm 0.003$ & $48.27 \pm 2.29$ & $30.30 \pm 0.43$ \\
\hline B1-20(B) & $72.03 \pm 0.27$ & $73.37 \pm 0.16$ & $0.072 \pm 0.017$ & $0.074 \pm 0.012$ & $62.23 \pm 3.65$ & $52.01 \pm 0.45$ \\
B2-12(B) & $55.46 \pm 0.55$ & $62.43 \pm 1.04$ & $0.222 \pm 0.013$ & $0.197 \pm 0.038$ & $62.21 \pm 1.56$ & $56.60 \pm 0.51$ \\
B3-80(B) & $58.48 \pm 0.19$ & $57.90 \pm 0.11$ & $0.304 \pm 0.010$ & $0.270 \pm 0.016$ & $67.96 \pm 1.85$ & $60.17 \pm 0.81$ \\
\hline C1-20(B) & $49.85 \pm 0.14$ & $50.02 \pm 0.35$ & $0.127 \pm 0.013$ & $0.111 \pm 0.014$ & $43.50 \pm 0.96$ & $26.72 \pm 1.99$ \\
C2-12(B) & $73.72 \pm 15.54$ & $60.56 \pm 2.66$ & $0.233 \pm 0.085$ & $0.268 \pm 0.006$ & $42.06 \pm 2.00$ & $24.70 \pm 1.21$ \\
C3-80(B) & $68.85 \pm 1.77$ & $67.10 \pm 0.27$ & $0.424 \pm 0.044$ & $0.373 \pm 0.003$ & $44.00 \pm 0.56$ & $31.70 \pm 1.88$ \\
\hline D1-20(W) & $64.28 \pm 0.60$ & $66.43 \pm 0.21$ & $0.206 \pm 0.008$ & $0.177 \pm 0.004$ & $59.93 \pm 0.99$ & $50.60 \pm 1.33$ \\
D2-12(W) & $43.07 \pm 0.21$ & $61.67 \pm 1.93$ & $0.312 \pm 0.039$ & $0.557 \pm 0.024$ & $56.13 \pm 1.52$ & $47.82 \pm 0.54$ \\
D3-80(W) & $40.13 \pm 0.63$ & $45.67 \pm 0.45$ & $0.266 \pm 0.009$ & $0.201 \pm 0.009$ & $59.01 \pm 1.02$ & $51.17 \pm 1.72$ \\
\hline E1-20(W) & $81.39 \pm 0.41$ & $67.56 \pm 0.21$ & $0.146 \pm 0.009$ & $0.097 \pm 0.008$ & $61.69 \pm 0.29$ & $31.76 \pm 0.74$ \\
E2-20(W) & $75.88 \pm 0.59$ & $73.03 \pm 0.74$ & $0.119 \pm 0.008$ & $0.095 \pm 0.022$ & $56.71 \pm 0.86$ & $24.66 \pm 2.29$ \\
\hline
\end{tabular}

The zeta potential is a measurement of the surface potential of suspended particles. Particles with a zeta potential greater than $\pm 30 \mathrm{mV}$ are considered to be stable, because the repulsive force of the same charge can avoid particle aggregation [20]. Table 2 shows that the zeta potential of the D group is smaller than that of the B group, probably because the ions in the buffer dissociate and affect the surface charge of the particles, and the $\mathrm{D}$ group is expected to have better stability.

Table 2. Zeta potential of transfersomes.

\begin{tabular}{cccc}
\hline - & Zeta $(\mathbf{m V})$ & & Zeta $(\mathbf{m V})$ \\
\hline B1-20(B) & $-1.93 \pm 0.24$ & D1-20(W) & $-19.53 \pm 0.91$ \\
B2-12(B) & $-6.29 \pm 0.47$ & D2-12(W) & $-59.90 \pm 0.20$ \\
B3-80(B) & $-0.54 \pm 0.08$ & D3-80(W) & $-23.93 \pm 0.31$ \\
\hline
\end{tabular}

In addition, the particle sizes of D1-20(W) $(64.28 \mathrm{~nm})$ were the largest in the D group, due to the hydrophilic-lipophilic balance (HLB) value of the edge activator. In general, the lower HLB value makes the particle size smaller. Afterwards, the ethanol content was compared. Table 1 shows that the content of ethanol increased and particle size also enlarged, but the entrapment efficiency significantly dropped after two weeks. It might be caused by the fact that increasing the ethanol content reduces the stability of the membrane, and thus decreases the entrapment efficiency. Based on the above results, there is no significant difference between the entrapment efficiency of B1 $(62.23 \%)$ and D1 $(59.93 \%)$, but D1 had a smaller particle size $(64.28 \mathrm{~nm})$ and zeta potential $(-19.53 \mathrm{mV})$ and, therefore, the following experiment was conducted in group D.

\subsection{Antioxidant Activity Assays}

Four antioxidant activity experiments were used to evaluate RSV and RSV transfersomes, including $\alpha$, $\alpha$-diphenyl- $\beta$-picrylhydrazyl (DPPH) radical scavenging activity assay, 2,2'-azino-bis (3-ethylbenzothiazoline-6-sulphonic acid) $\left(\mathrm{ABTS}^{+}\right)$radical cation scavenging activity assay, total phenolic content and reducing power. The results (Figures 1-4) show that the antioxidant activity of transfersomes was comparable to that of RSV, indicating that RSV antioxidant activity is not affected after coating. It was also proved that RSV did not lose its activity during the coating process, further confirming that the preparation method of this experiment was successful. 


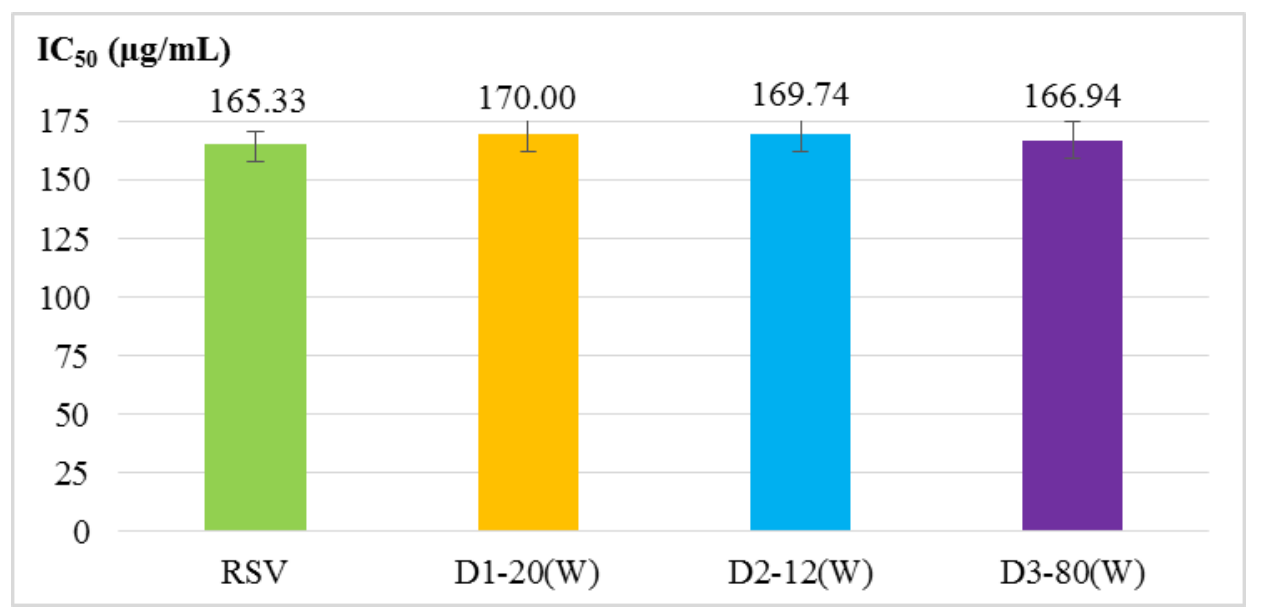

Figure 1. DPPH radical scavenging activity of RSV and RSV transfersomes (D1-20(W), D2-12(W), and D3-80(W) groups). The $\mathrm{IC}_{50}$ value is the sample to remove the $50 \% \mathrm{DPPH}$ radicals $\left(2.4 \times 10^{-4} \mathrm{M}\right)$ required concentration. The values are means $\pm \mathrm{SD}$.

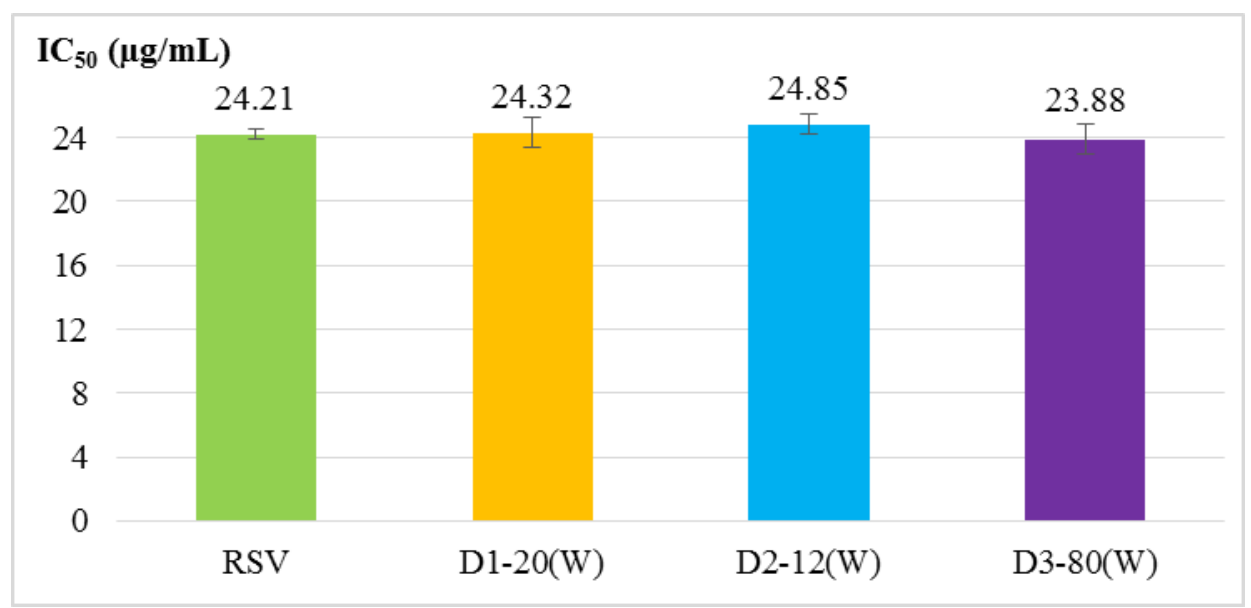

Figure 2. $\mathrm{ABTS}^{+}$radical scavenging activity of RSV and RSV transfersomes (D1-20(W), D2-12(W), and $\mathrm{D} 3-80(\mathrm{~W})$ groups). The $\mathrm{IC}_{50}$ value is the sample to remove the $50 \% \mathrm{ABTS}^{+}$radical cations $\left(7 \times 10^{-3} \mathrm{M}\right)$ required concentration. The values are means $\pm \mathrm{SD}$.

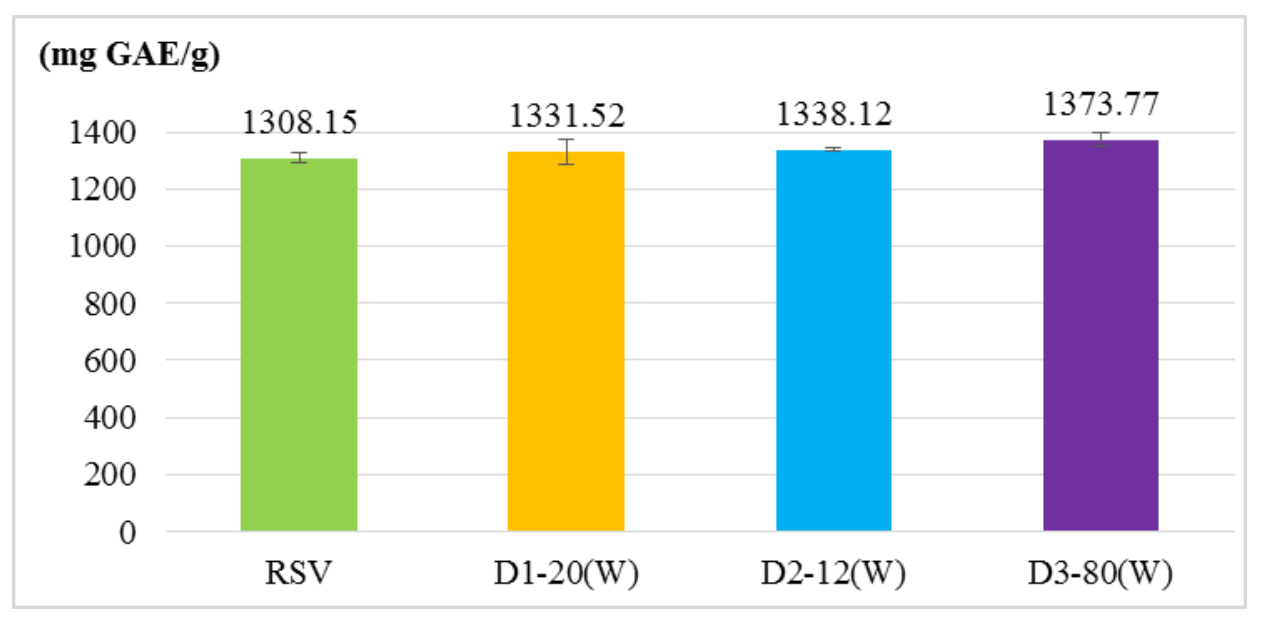

Figure 3. Total phenolic content of RSV and RSV transfersomes (D1-20(W), D2-12(W), and D3-80(W) groups). Total flavonoid content was measured by the Folin-Ciocalteu method and the results are presented as gallic acid equivalent (GAE). The $40 \mu \mathrm{L}$ of sample was reacted with $40 \mu \mathrm{L}$ of $2 \mathrm{~N}$ Folin-Ciocalteu reagent in a total volume of $600 \mu \mathrm{L}$. The values are means $\pm \mathrm{SD}$. 


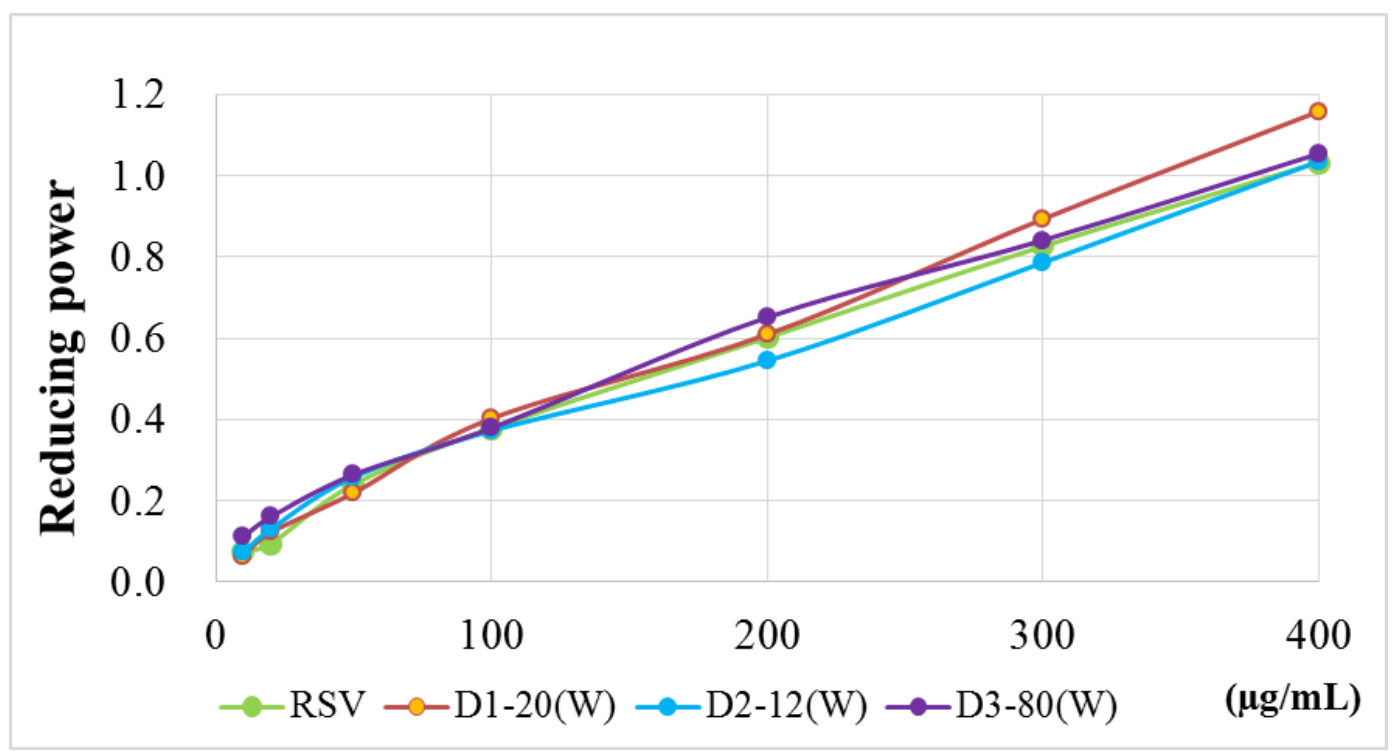

Figure 4. Reducing power of RSV and RSV transfersomes (D1-20(W), D2-12(W), and D3-80(W) groups). The ability of samples with various concentrations reduced $1 \%$ potassium ferricyanide $\left(\mathrm{K}_{3} \mathrm{Fe}(\mathrm{CN})_{6}\right)$ is presented as the reducing power.

\subsection{In Vitro Transdermal Delivery Analysis}

In vitro drug release profiles are presented in Figure 5 . It can be seen that the accumulative penetration of D1-20(W), D2-12(W), and D3-80(W) was higher than the unencapsulated RSV group $\left(4.06 \mu \mathrm{g} / \mathrm{cm}^{2}\right)$, and the highest accumulation of D1-20(W) was $5.18 \mu \mathrm{g} / \mathrm{cm}^{2}$ at $6 \mathrm{~h}$. This shows that RSV can penetrate the skin more easily after encapsulation. This phenomenon was due to the addition of edge activators to the transfersomes, thereby increasing its ultradeformability and penetrability. Additionally, the penetration of D1-20(W) was higher than D3-80(W), the same type of edge activators, based on the carbon chain length. The carbon chain length of Tween 20 was shorter than Tween 80, so its higher ultradeformability made it easier for drugs to penetrate the skin.

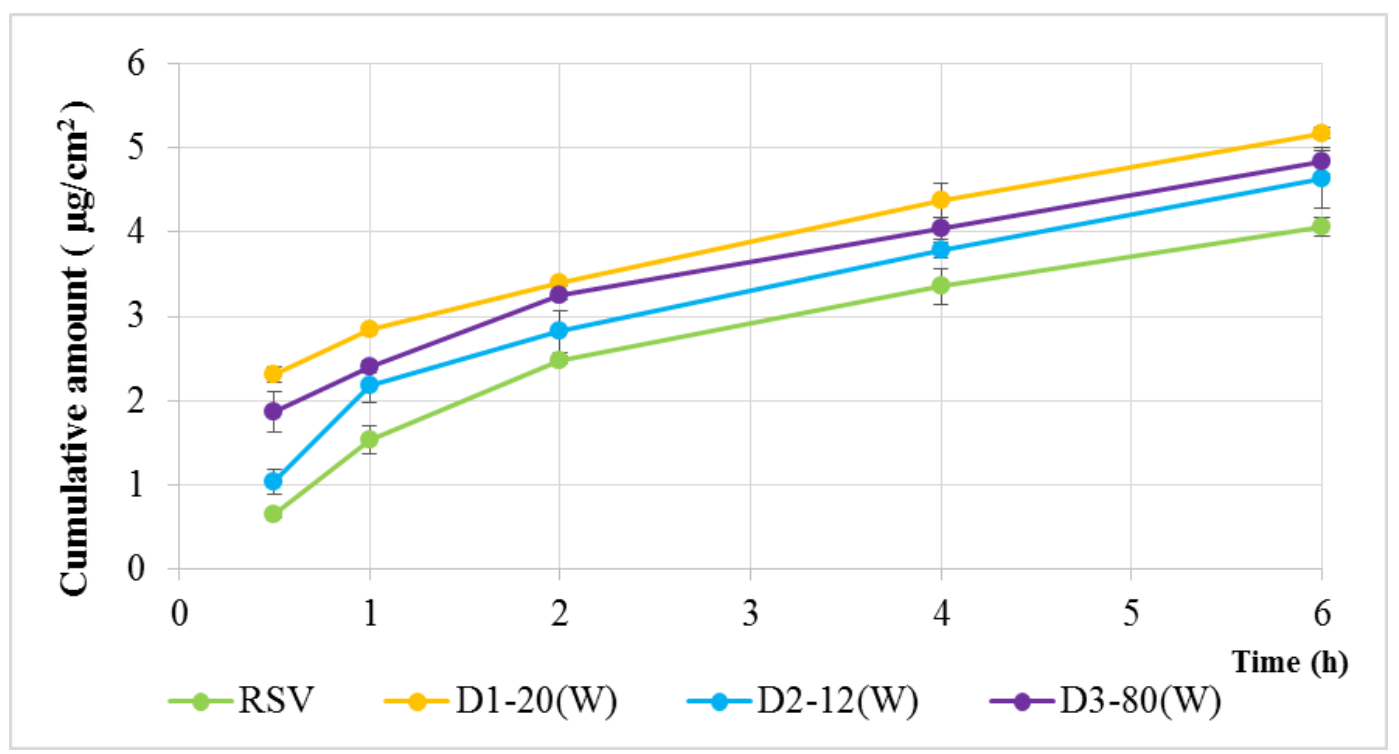

Figure 5. In vitro release profiles of RSV and RSV transfersomes (D1-20(W), D2-12(W), and D3-80(W) groups). The sample with $1.0 \mathrm{~mL}$ was placed in the donor site and $5.0 \mathrm{~mL}$ consisting of PBS and ethanol $(70: 30, v / v)$ was put into the receptor site. These sites were separated with a $0.785 \mathrm{~cm}^{2}$ Strat-M ${ }^{\circledR}$ Membrane. The cumulative amount of RSV was analyzed in each time points. 


\subsection{Cell Viability Assay}

This study was conducted using different concentrations of RSV $(20,40,60,80,100 \mu \mathrm{M})$ and transfersomes $(40,60,80 \mu \mathrm{M})$. The cell viability (MTT assay) is shown in Figure 6. It was found that the cell viabilities of the transfersomes were all higher than $83 \%$, among which D3-80(W) had the lowest cytotoxicity. Moreover, if the resveratrol concentrations of transfersomes are lower than $40 \mu \mathrm{M}$, almost no cytotoxicity is observed (data not shown). However, compared with the same concentration of RSV $(40$ to $80 \mu \mathrm{M})$, the cytotoxicity of transfersome was significantly reduced. The results demonstrate that RSV can diminish its cytotoxicity after the encapsulation; therefore, transfersomes are safer than RSV.

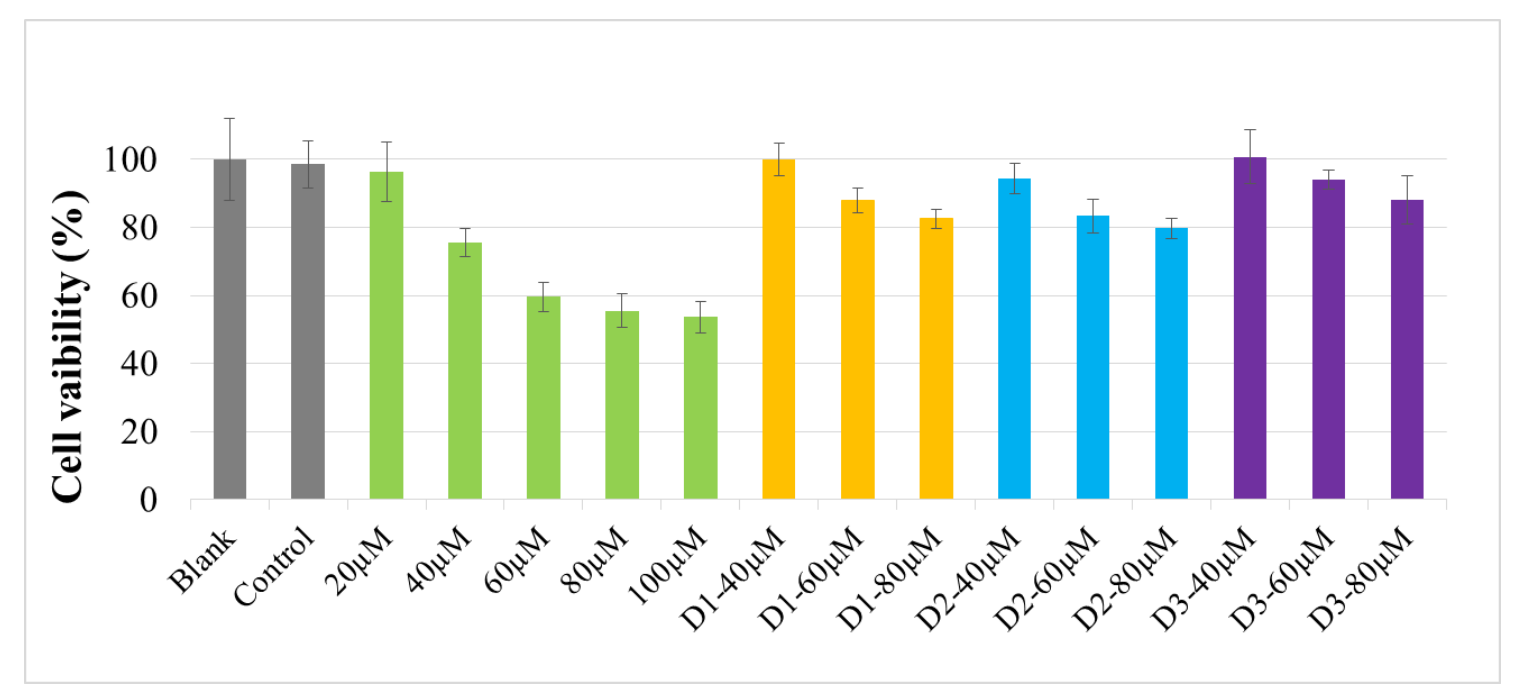

Figure 6. Cell viability of RSV and RSV transfersomes (D1-20(W), D2-12(W), and D3-80(W) groups). The cell viability of B16-F10 cells was analyzed by MTT assay after $24 \mathrm{~h}$ treatment. The values are means \pm SD.

\section{Discussion}

Resveratrol has poor water solubility, instability, and also low bioavailability; thus, its applications were restricted by these features. Additionally, there have not yet been any studies focused on the development of RSV transfersome. Therefore, it is important that we try to encapsulate the RSV into transfersome, which may have potential application for cosmetics, foods and drugs.

In this study, we successfully prepared transfersomes using a high-pressure homogenization technique. Concluding the tested parameters, the best production condition was 5\% PC/EA (3:1) and $5 \%$ ethanol in distilled water, with an ultrasonic bath and stirring at $500 \mathrm{rpm}$, followed by high-pressure homogenization (1500 bar). Therefore, these conditions were used to compare the three edge activators Tween 20, Plantacare ${ }^{\circledR} 1200$ UP. and Tween 80.

According to the evaluation of particle size, entrapment efficiency and stability, the optimal particle size of D3-80(W) was $40.13 \pm 0.51 \mathrm{~nm}$. The entrapment efficiency of D1-20(W) was not significantly different from D3-80(W). The results of antioxidant activity analysis showed that there was no significant difference between the RSV transfersomes and RSV group (unencapsulated), indicating that RSV antioxidant activity is not affected after coating. Although the antioxidative activity of RSV transfersome is not enhanced by the encapsulation process, the solubility and stability might be improved by transfersome, and it is still supposed that the transfersome encapsulation is a good strategy for the application of RSV [21,22].

In the in vitro transdermal delivery analysis, after $6 \mathrm{~h}, \mathrm{D} 1-20(\mathrm{~W})$ had the highest accumulation penetration, $5.18 \mu \mathrm{g} / \mathrm{cm}^{2}$, which was $27.5 \%$ more than that of the RSV group (Figure 5), confirming that transfersomes can significantly improve the transdermal delivery capacity of the active ingredient. The in vitro transdermal delivery analysis may simulate the situation of active compounds which be 
absorbed across the real skin. Therefore, this result also indicated that the application of RSV in the future might improve the bioavailability in many respects, including cosmetics, foods, and drugs.

For the application of active ingredients in cosmetics and foods, and also in drugs, it is very important that safety should be the primary concern [23]. Our cytotoxicity assay showed that the cell viability of transfersome-treated cells improved, and the cytotoxicity of the D3-80(W) group decreased by about $34.45 \%$ when compared with the same concentration of RSV (Figure 6), demonstrating that transfersomes can reduce the cytotoxicity of RSV. Therefore, the above results prove that the transfersome encapsulation cannot only effectively increase the penetrating accumulation of resveratrol but also benefit its safety.

\section{Materials and Methods}

\subsection{Materials}

Resveratrol was provided by Shaanxi Huifeng Pharmaceutical Co., Ltd. (Xi'an, China). Acetic acid and potassium hexacyanoferrate $\left(\mathrm{K}_{3} \mathrm{Fe}(\mathrm{CN})_{6}\right)$ were purchased from Honeywell (Seelze, Germany). Dipotassium hydrogenphosphate $\left(\mathrm{K}_{2} \mathrm{HPO}_{4}\right)$, potassium phosphate $\left(\mathrm{KH}_{2} \mathrm{PO}_{4}\right)$ and sodium phosphate $\left(\mathrm{Na}_{2} \mathrm{HPO}_{4}\right)$ were supplied by J.T. Baker ${ }^{\circledR}$ (Phillipsburg, NJ, USA). Ethanol was obtained from Echo Chemical (Miaoli, Taiwan). Folin-Ciocalteu's phenol reagent, trichloroethanoic acid (TCA), $\alpha$, $\alpha$-diphenyl- $\beta$-picrylhydrazyl (DPPH), and 3-(4,5-dimethyl-2-thiazolyl)-2,5-diphenyl-2H-tetrazolium bromide (MTT) were purchased from Sigma-Aldrich (St. Louis, MO, USA). Gallic acid was provided by MP BIOMEDICALS (USA). Iron trichloride $\left(\mathrm{FeCl}_{3}\right)$ and sodium carbonate $\left(\mathrm{Na}_{2} \mathrm{CO}_{3}\right)$ were obtained from Kanto Chemical Co., Inc. (Japan). Methanol was purchased from Aencore (Australia). Polysorbate 20 (Tween20) and polysorbate 80 (Tween80) were supplied by Croda (City, UK). 2,2'-azino-bis (3-ethylbenzothiazoline-6-sulphonic acid) (ABTS) was purchased from Tokyo Chemical Industry Co., Ltd. (Tokyo, Japan). Sodium phosphate monobasic $\left(\mathrm{NaH}_{2} \mathrm{PO}_{4}\right)$ was provided by Choneye Pure Chemicals (Taipei, Taiwan). Kalium peroxodisulfate $\left(\mathrm{K}_{2} \mathrm{~S}_{2} \mathrm{O}_{8}\right)$ was obtained from Acros Organics (Morris Plains, NJ, USA). Lauryl glucoside (Plantacare ${ }^{\circledR} 1200$ UP) was provided by BASF (Ludwigshafen, Germany). Lecithin (Emulmetik ${ }^{\mathrm{TM}}$ 900) was purchased from Lucas Meyer Cosmetics (Champlan, France).

\subsection{Preparation of Transfersome}

First, different proportions of lecithin and edge activators (Table 3) were uniformly dispersed in PBS buffer (pH 6.8) [24] or distilled water containing various contents of alcohol for $3 \mathrm{~h}$ with ultrasonic shaking by an ultrasonic bath (DC 300H, DELTA, New Taipei City, Taiwan) and stirring at $500 \mathrm{rpm}$. Second, the mixture underwent intermittent ultrasonic shaking ( $2 \mathrm{~s}$ on, $2 \mathrm{~s}$ off). The mixture was homogenized in five cycles with a high-pressure homogenizer (APV-2000, SPXFLOW, UK) at 1500 bar. Finally, samples were stored in a dark room at $25^{\circ} \mathrm{C}$ [25]. 
Table 3. Changeable experimental parameters to affect transfersome.

\begin{tabular}{|c|c|c|c|c|c|c|c|c|}
\hline \multirow[b]{2}{*}{ No. } & \multicolumn{8}{|c|}{ Composition $(\% W / V)$} \\
\hline & RSV & $\begin{array}{l}\text { Emulmetik } \\
900\end{array}$ & Tween-20 & 1200UP & Tween-80 & Ethanol & PBS Buffer & $\begin{array}{c}\text { Distilled } \\
\text { Water }\end{array}$ \\
\hline A1-20(B) & 0.2 & 3.33 & 1.67 & & & 5.00 & q.s. to 100 & \\
\hline A2-12(B) & 0.2 & 3.33 & & 1.67 & & 5.00 & q.s. to 100 & \\
\hline A3-80(B) & 0.2 & 3.33 & - & - & 1.67 & 5.00 & q.s. to 100 & \\
\hline B1-20(B) & 0.2 & 3.75 & 1.25 & & & 5.00 & q.s. to 100 & - \\
\hline B2-12(B) & 0.2 & 3.75 & & 1.25 & & 5.00 & q.s. to 100 & \\
\hline B3-80(B) & 0.2 & 3.75 & - & - & 1.25 & 5.00 & q.s. to 100 & \\
\hline C1-20(B) & 0.2 & 4.00 & 1.00 & & & 5.00 & q.s. to 100 & - \\
\hline C2-12(B) & 0.2 & 4.00 & & 1.00 & & 5.00 & q.s. to 100 & \\
\hline C3-80(B) & 0.2 & 4.00 & - & - & 1.00 & 5.00 & q.s. to 100 & - \\
\hline D1-20(W) & 0.2 & 3.75 & 1.25 & & & 5.00 & & q.s. to 100 \\
\hline D2-12(W) & 0.2 & 3.75 & & 1.25 & & 5.00 & & q.s. to 100 \\
\hline D3-80(W) & 0.2 & 3.75 & - & - & 1.25 & 5.00 & - & q.s. to 100 \\
\hline E1-20(W) & 0.2 & 3.75 & 1.25 & & & 10.00 & - & q.s. to 100 \\
\hline E2-20(W) & 0.2 & 3.75 & 1.25 & - & - & 20.00 & - & q.s. to 100 \\
\hline
\end{tabular}

\subsection{Particle Sizes and Zeta Potential of Transfersome}

Dynamic light scattering (DLS) is one of the standard methods for measuring particle sizes in fluids. This method is based on the examination of random particle movement due to constant Brownian motion [26]. Particle size and zeta potential were assessed by DLS and electrophoretic light scattering (ELS) using a dynamic light scattering nanoparticle size analysis (Malvern Zetasizer Nano ZS, Malvern Instruments Ltd., Malvern, UK).

\subsection{Entrapment Efficiency of Resveratrol}

The sample was centrifuged at 10,000 rpm for $15 \mathrm{~min}$, and the supernatant was diluted with methanol. The sample was filtered by Phree ${ }^{\mathrm{TM}}$ Phospholipid Removal (Phenomenex, Torrance, CA, USA) to remove impurities and phospholipids and determine the concentrations of RSV by HPLC (Pump: V6815, UV-VIS: V6830, KNAUER, Berlin, Germany). RSV separation was carried out on a C18 column (Kinetex 5u EVO C18 100A $250 \times 4.6 \mathrm{~mm}$, Phenomenex, Torrance, CA, USA) using a mobile phase consisting of methanol containing $0.5 \%$ acetic acid in water $(80: 20, v / v)$ at a flow rate of $0.8 \mathrm{~mL} / \mathrm{min}$. The detection wavelength was set at $310 \mathrm{~nm}$.

The RSV EE was calculated by Equation (1) [27]:

$$
\mathrm{EE}(\%)=\left(\frac{\text { total RSV amount }- \text { free RSV amount }}{\text { total RSV amount }}\right) \times 100
$$

\subsection{Stability of Transfersome}

The transfersome samples were stored at $25{ }^{\circ} \mathrm{C}$ and dark for 14 days. Then the stability was evaluated by its entrapment efficiency, particle size, and PDI.

\subsection{Antioxidant Activity Evaluation}

\subsubsection{DPPH Radical Scavenging Activity Assay}

When the sample reacted with DPPH, hydrogen was added to inhibit the oxidation chain reaction. At this time, the DPPH solution changed its color from purple to yellow. This experiment used the $\mathrm{IC}_{50}$ comparison sample to remove the 50\% DPPH required concentration. Twenty microliters of varying concentrations of sample solution were added to $180 \mu \mathrm{L}$ of $2.4 \times 10^{-4} \mathrm{M}$ DPPH solution. The mixing solutions were incubated in dark at room temperature for $30 \mathrm{~min}$, and the absorbance at $517 \mathrm{~nm}$ was 
recorded by an ELISA-reader (MQX-200, BioTek, Winooski, VT, USA). All determinations were carried out in triplicate.

The radical scavenging rate was calculated by Equation (2) [28]:

$$
\mathrm{DPPH} \text { scavenging rate }(\%)=\left(\frac{\mathrm{A} 0-\mathrm{Ai}}{\mathrm{A} 0}\right) \times 100
$$

where $\mathrm{A} 0$ is the absorbance of blank, and Ai is the absorbance of the sample.

\subsection{2. $\mathrm{ABTS}^{+}$Radical Cation Scavenging Activity Assay}

The peroxidase catalyzes the oxidation reaction between $\mathrm{ABTS}^{+}$and $\mathrm{H}_{2} \mathrm{O}_{2}$, forming a stable blue-green water-soluble $\mathrm{ABTS}^{+}$cation radical. When the $\mathrm{ABTS}^{+}$cation radical is reduced by an antioxidant or combined with another radical, the absorbance value decreases or disappears. Twenty microliters of varying concentrations of sample solution were added to $180 \mu \mathrm{L}$ of $7 \times 10^{-3} \mathrm{M} \mathrm{ABTS}^{+}$ solution. The mixing solutions were incubated in the dark at room temperature for $10 \mathrm{~min}$, and the absorbance at $734 \mathrm{~nm}$ was recorded by an ELISA-reader (MQX-200, BioTek, Winooski, VT, USA). All determinations were carried out in triplicate.

The radical scavenging rate was calculated by Equation (3):

$$
\mathrm{ABTS}^{+} \text {radical cation scavenging rate }(\%)=\left(\frac{\mathrm{A} 0-\mathrm{Ai}}{\mathrm{A} 0}\right) \times 100 \%
$$

where $\mathrm{A} 0$ is the absorbance of blank; $\mathrm{Ai}$ is the absorbance of the sample.

\subsubsection{Total Phenolic Content}

Total flavonoid content was measured by the Folin-Ciocalteu method. The phenolic acid compounds have easily oxidizable hydroxyl groups, and phosphomolybdic acid in the Folin-Ciocalteu reagent will oxidize it and reduce itself to form a blue compound. In our study, the calibration curve was established using gallic acid as a standard. To the $40 \mu \mathrm{L}$ of sample, we added $520 \mu \mathrm{L}$ of distilled water and $40 \mu \mathrm{L}$ of $2 \mathrm{~N}$ Folin-Ciocalteu reagent, and this was shaken for $6 \mathrm{~min}$. Afterwards, we added $400 \mu \mathrm{L}$ of $7 \% \mathrm{Na}_{2} \mathrm{CO}_{3}$ and incubated it in the dark at room temperature for $90 \mathrm{~min}$; the absorbance at $750 \mathrm{~nm}$ was recorded by an ELISA-reader (MQX-200, BioTek, Winooski, VT, USA). The total phenol content of the sample could be determined by comparing the calibration curve of gallic acid (GAE). All determinations were carried out in triplicate.

\subsubsection{Reducing Power}

Antioxidants reduced potassium ferricyanide $\left(\mathrm{K}_{3} \mathrm{Fe}(\mathrm{CN})_{6}\right)$ to potassium ferrocyanide $\left(\mathrm{K}_{4} \mathrm{Fe}(\mathrm{CN})_{6}\right)$, and potassium ferrocyanide reacted with $\mathrm{Fe}^{+}$to form Prussian blue. Three hundred microliters of varying concentrations of sample solution were added to $300 \mu \mathrm{L}$ of $0.2 \mathrm{M}$ potassium phosphate buffer (pH 6.6) and $300 \mu \mathrm{L}$ of $1 \% \mathrm{~K}_{3} \mathrm{Fe}(\mathrm{CN})_{6}$ for $20 \mathrm{~min}$ at $50{ }^{\circ} \mathrm{C}$. After cooling to room temperature, $300 \mu \mathrm{L}$ of $10 \%$ TCA was added and centrifuged at $3000 \mathrm{rpm}$ for $20 \mathrm{~min}$. The supernatant was added to $500 \mu \mathrm{L}$ of distilled water and $100 \mu \mathrm{L}$ of $0.1 \% \mathrm{FeCl}_{3}$. The mixing solutions were incubated in the dark for 10 min and the absorbance at $700 \mathrm{~nm}$ was recorded by an ELISA-reader (MQX-200, BioTek, Winooski, VT, USA). All determinations were carried out in triplicate.

The reducing power was calculated by Equation (4):

$$
\text { Reducing power }=\mathrm{Ai}-\mathrm{A} 0
$$

where $\mathrm{A} 0$ is the absorbance of blank; $\mathrm{Ai}$ is the absorbance of the sample. 


\subsection{In Vitro Transdermal Delivery Analysis}

The transdermal drug delivery system has been widely used in the human body to absorb in vitro release. The release of transfersomes was tested by a Franz type diffusion cell (Logan FDC-6, Somerset, NJ, USA). The cell consisted of two compartments, the donor and the receptor sections. These sections were separated with a $0.785 \mathrm{~cm}^{2}$ Strat- $\mathrm{M}^{\circledR}$ Membrane (Merck, Darmstadt, Germany) and hydrated with PBS (pH 7.4) and ethanol (70:30, v/v) [17] for $30 \mathrm{~min}$. A $1.0 \mathrm{~mL}$ transfersome was placed in the donor site and $5.0 \mathrm{~mL}$ consisting of PBS and ethanol $(70: 30, v / v)$ was poured into the receptor site. The Franz type diffusion cells were stirred at $36.7 \pm 0.3{ }^{\circ} \mathrm{C}$ with magnetic stirrers. Aliquots of $300 \mu \mathrm{L}$ were withdrawn at various time intervals $(0.5,1,2,4,6 \mathrm{~h})$ and replaced by the same volume of fresh medium. The amount of released RSV was passed through a $0.45 \mu \mathrm{m}$ polytetrafluoroethylene (PTFE) membrane filter, and the amount of released RSV was measured by high-performance liquid chromatography.

\subsection{Cell Culture and Cell Viability Assay}

The cell line used in this experiment was B16-F10 (BCRC 60031) mouse melanoma cells purchased from the Food Industry Research and Development Institute (Hsinchu, Taiwan). B16-F10 cells were seeded at a density of $6 \times 10^{3}$ cell/well in a 96-well plate and maintained in $100 \mu \mathrm{L}$ Dulbecco's modification of Eagle medium (DMEM) supplemented with $10 \%$ PBS for $24 \mathrm{~h}$ in a humidified incubator $\left(37^{\mathrm{O}} \mathrm{C}, 5 \% \mathrm{CO}_{2}\right)$. Each well was then treated with RSV and RSV transfersomes at serial concentrations. After being cultured for $24 \mathrm{~h}, 100 \mu \mathrm{L}(1.0 \mathrm{mg} / \mathrm{mL})$ of MTT solution was added into each well for $30 \mathrm{~min}$ to allow the formation of formazan crystal. Subsequently, supernatant was removed carefully and $100 \mu \mathrm{L}$ DMSO was added to each well. Cell viabilities were evaluated using an ELISA-reader (MQX-200, BioTek, Winooski, VT, USA) at $540 \mathrm{~nm}$.

\subsection{Statistical Analysis}

All tests were performed in triplicates. The values are presented as means \pm SD of three replicates. The statistically significant differences were evaluated by the Student's test.

\section{Conclusions}

Our results demonstrate that transfersome improves the instability, solubility, bioavailability, and safety of RSV. For the in vitro transdermal delivery, D1-20(W) had the highest cumulative amounts. For cell viability, the D3-80(W) group had the lowest cytotoxicity. The results indicated that the RSV transfersomes D1-20(W) and D3-80(W) are the best groups. Therefore, applications of RSV transfersomes in the fields of cosmetics, foods and drugs will be considered as a potential formulation in the future.

Author Contributions: P.-S.W., Y.-C.K. and C.-C.L. conceived and designed the experiments; Y.-S.L. and Y.-C.K. performed the experiments; Y.-C.K., P.-S.W., and S.-J.J.T. analyzed the data; and Y.-S.L. and C.-C.L. wrote the paper.

Funding: This research was funded by the Ministry of Science and Technology, Taiwan (MOST 105-2632-M-126-001; MOST 106-2632-M-126-001; MOST 107-2632-M-126-001).

Conflicts of Interest: The authors declare no conflict of interest.

\section{References}

1. R Neves, A.; Lucio, M.; LC Lima, J.; Reis, S. Resveratrol in medicinal chemistry: A critical review of its pharmacokinetics, drug-delivery, and membrane interactions. Curr. Med. Chem. 2012, 19, 1663-1681. [CrossRef]

2. Gambini, J.; Inglés, M.; Olaso, G.; Lopez-Grueso, R.; Bonet-Costa, V.; Gimeno-Mallench, L.; Mas-Bargues, C.; Abdelaziz, K.; Gomez-Cabrera, M.; Vina, J. Properties of resveratrol: In vitro and in vivo studies about metabolism, bioavailability, and biological effects in animal models and humans. Oxid. Med. Cell. Longev. 2015. [CrossRef] [PubMed] 
3. Švajger, U.; Jeras, M. Anti-inflammatory effects of resveratrol and its potential use in therapy of immune-mediated diseases. Int. Rev. Immunol. 2012, 31, 202-222. [CrossRef] [PubMed]

4. Ko, J.-H.; Sethi, G.; Um, J.-Y.; Shanmugam, M.K.; Arfuso, F.; Kumar, A.P.; Bishayee, A.; Ahn, K.S. The role of resveratrol in cancer therapy. Int. J. Mol. Sci. 2017, 18, 2589. [CrossRef] [PubMed]

5. Mondal, A.; Bennett, L.L. Resveratrol enhances the efficacy of sorafenib mediated apoptosis in human breast cancer mcf7 cells through ros, cell cycle inhibition, caspase 3 and parp cleavage. Biomed. Pharmacother. 2016, 84, 1906-1914. [CrossRef] [PubMed]

6. Bastianetto, S.; Ménard, C.; Quirion, R. Neuroprotective action of resveratrol. Biochim. Biophys. Acta (BBA)-Mol. Basis Disease 2015, 1852, 1195-1201. [CrossRef] [PubMed]

7. Gresele, P.; Cerletti, C.; Guglielmini, G.; Pignatelli, P.; de Gaetano, G.; Violi, F. Effects of resveratrol and other wine polyphenols on vascular function: An update. J. Nutr. Biochem. 2011, 22, 201-211. [CrossRef]

8. Cianciulli, A.; Calvello, R.; Cavallo, P.; Dragone, T.; Carofiglio, V.; Panaro, M.A. Modulation of nf-kb activation by resveratrol in lps treated human intestinal cells results in downregulation of pge2 production and cox-2 expression. Toxicol. Vitro 2012, 26, 1122-1128. [CrossRef]

9. Robinson, K.; Mock, C.; Liang, D. Pre-formulation studies of resveratrol. Drug Dev. Ind. Pharm. 2015, 41, 1464-1469. [CrossRef]

10. Zupančič, Š.; Lavrič, Z.; Kristl, J. Stability and solubility of trans-resveratrol are strongly influenced by ph and temperature. Eur. J. Pharm. Biopharm. 2015, 93, 196-204. [CrossRef]

11. Meybeck, A. Past, present and future of liposome cosmetics. In Liposome Dermatics; Springer: Heidelberg/Berlin, Germany, 1992; pp. 341-345.

12. Jia, H.J.; Jia, F.Y.; Zhu, B.J.; Zhang, W.P. Preparation and characterization of glycyrrhetinic-acid loaded peg-modified liposome based on peg-7 glyceryl cocoate. Eur. J. Lipid Sci. Technol. 2017, 119. [CrossRef]

13. Pirvu, C.D.; Hlevca, C.; Ortan, A.; Prisada, R. Elastic vesicles as drugs carriers through the skin. Farmacia 2010, 58, 128-135.

14. Zhang, Y.; Shen, L.; Zhang, K.; Guo, T.; Zhao, J.; Li, N.; Feng, N. Enhanced antioxidation via encapsulation of isooctyl p-methoxycinnamate with sodium deoxycholate-mediated liposome endocytosis. Int. J.Pharm. 2015, 496, 392-400. [CrossRef] [PubMed]

15. Honeywell-Nguyen, P.L.; Bouwstra, J.A. Vesicles as a tool for transdermal and dermal delivery. Drug Discov. Today Technol. 2005, 2, 67-74. [CrossRef] [PubMed]

16. El Maghraby, G.; Williams, A.C.; Barry, B. Interactions of surfactants (edge activators) and skin penetration enhancers with liposomes. Int. J. Pharm. 2004, 276, 143-161. [CrossRef] [PubMed]

17. Scognamiglio, I.; De Stefano, D.; Campani, V.; Mayol, L.; Carnuccio, R.; Fabbrocini, G.; Ayala, F.; La Rotonda, M.I.; De Rosa, G. Nanocarriers for topical administration of resveratrol: A comparative study. Int. J. Pharm. 2013, 440, 179-187. [CrossRef] [PubMed]

18. Chaudhary, H.; Kohli, K.; Kumar, V. Nano-transfersomes as a novel carrier for transdermal delivery. Int. J. Pharm. 2013, 454, 367-380. [CrossRef]

19. El Zaafarany, G.M.; Awad, G.A.; Holayel, S.M.; Mortada, N.D. Role of edge activators and surface charge in developing ultradeformable vesicles with enhanced skin delivery. Int. J. Pharm. 2010, 397, 164-172. [CrossRef]

20. Zhao, L.; Temelli, F.; Curtis, J.M.; Chen, L. Preparation of liposomes using supercritical carbon dioxide technology: Effects of phospholipids and sterols. Food Res. Int. 2015, 77, 63-72. [CrossRef]

21. Banu, R.; Gerding, J.; Franklin, C.; Sikazwe, D.; Horton, W.; Török, M.; Davis, J.; Cheng, K.; Nakazwe, M.; Mochona, B. 4,5-dimethoxy-2-nitrobenzohydrazides and 1-(1-benzylpiperidin-4-yl)ethan-1-ones as potential antioxidant/cholinergic endowed small molecule leads. Sci. Pharm. 2018, 86, 2. [CrossRef]

22. Strugała, P.; Tronina, T.; Huszcza, E.; Gabrielska, J. Bioactivity in vitro of quercetin glycoside obtained in beauveria bassiana culture and its interaction with liposome membranes. Molecules 2017, 22, 1520. [CrossRef] [PubMed]

23. Rachmawati, H.; Novel, M.; Ayu, S.; Berlian, G.; Tandrasasmita, O.; Tjandrawinata, R.; Anggadiredja, K. The in vitro-in vivo safety confirmation of peg-40 hydrogenated castor oil as a surfactant for oral nanoemulsion formulation. Sci. Pharm 2017, 85, 18. [CrossRef] [PubMed]

24. Yusuf, M.; Sharma, V.; Pathak, K. Nanovesicles for transdermal delivery of felodipine: Development, characterization, and pharmacokinetics. Int. J. Pharm. Investig. 2014, 4. [CrossRef] 
25. Guldiken, B.; Gibis, M.; Boyacioglu, D.; Capanoglu, E.; Weiss, J. Physical and chemical stability of anthocyanin-rich black carrot extract-loaded liposomes during storage. Food Res. Int. 2018, 108, 491-497. [CrossRef] [PubMed]

26. de Kanter, M.; Meyer-Kirschner, J.; Viell, J.; Mitsos, A.; Kather, M.; Pich, A.; Janzen, C. Enabling the measurement of particle sizes in stirred colloidal suspensions by embedding dynamic light scattering into an automated probe head. Measurement 2016, 80, 92-98. [CrossRef]

27. Sanna, V.; Roggio, A.M.; Pala, N.; Marceddu, S.; Lubinu, G.; Mariani, A.; Sechi, M. Effect of chitosan concentration on plga microcapsules for controlled release and stability of resveratrol. Int.J. Biol. Macromol. 2015, 72, 531-536. [CrossRef] [PubMed]

28. Hao, J.; Guo, B.; Yu, S.; Zhang, W.; Zhang, D.; Wang, J.; Wang, Y. Encapsulation of the flavonoid quercetin with chitosan-coated nano-liposomes. LWT-Food Sci. Technol. 2017, 85, 37-44. [CrossRef]

Sample Availability: Samples of the compounds are not available from the authors.

(C) 2019 by the authors. Licensee MDPI, Basel, Switzerland. This article is an open access article distributed under the terms and conditions of the Creative Commons Attribution (CC BY) license (http://creativecommons.org/licenses/by/4.0/). 